\title{
TCF7L2 correlation in both insulin secretion and postprandial insulin sensitivity
}

\author{
Mari Cassol Ferreira ${ }^{1,2^{*}}$, Maria Elizabeth Rossi da Silva ${ }^{1}$, Rosa Tsuneshiro Fukui ${ }^{1}$, Maria \\ do Carmo Arruda-Marques ${ }^{1}$ and Rosa Ferreira dos Santos ${ }^{1}$
}

\begin{abstract}
Background: The TCF7L2 rs7903146 variant is strongly associated with type 2 diabetes mellitus (T2DM). However, the mechanisms involved in this association remain unknown and may include extrapancreatic effects. The aim of this study was to perform a metabolic characterization of T2DM patients with and without the TCF7L2 rs7903146 riskT allele and analyze some influences of the TCF7L2 genotype on glucose metabolism.

Methods: Patients with T2DM ( $n=162)$ were genotyped for the TCF7L2 rs7903146 single nucleotide polymorphism. Individuals with CT/TT and CC genotypes were compared regarding basal serum levels of glucose, glycosylated hemoglobin A1C, HDL, uric acid, insulin, and C-peptide. A subset of 56 individuals was evaluated during a 500-calorie mixed-meal test with measurements of glucose, insulin, proinsulin, C-peptide and glucagon. Additional secondary assessments included determination of insulinogenic index $\left(\left.\mathrm{IG}\right|_{30}\right)$, and insulin sensitivity (\%S) and resistance (IR) by Homeostatic model assessment (HOMA).

Results: Patients with the CT/TT genotype showed lower baseline plasma concentrations of C-peptide when compared with those with the CC genotype. Of the 56 individuals who participated in the mixed-meal test, 26 and 30 had the CC and CT/TT genotypes, respectively. CT/TT subjects, compared with CC individuals, had higher post prandial plasma levels of insulin and C-peptide at 30-120 $\mathrm{min}(p<0.05)$ and proinsulin at 45-240 min $(p<0.05)$. Interestingly CT/TT individuals presented at baseline higher \%S $(p=0.021)$, and lower IR $(p=0.020)$ than CC individuals. No significant differences in $\mathrm{IGI}_{30}$ values were observed between groups.

Conclusions: The T2DM individuals carrying the rs7903146 T allele of the TCF7L2 gene presented higher IR pattern in response to a mix-meal test, different of beta cell function at baseline assessed by C-peptide levels which was lower, and Homa-IR was lower when comparing with non-carriers.
\end{abstract}

Keywords: Type 2 diabetes mellitus, Insulin resistance, Polymorphism, genetic, Polymorphism, single nucleotide, Glucose metabolism disorders, Hyperglycemia, postprandial

\section{Background}

Type 2 diabetes (T2DM) is a result of a complex interplay between genetic and environmental factors interfering with glucose and fat metabolism. The disease involves multiple defects in peripheral (muscle) and hepatic insulin action, insulin secretion, adipose tissue metabolism, whole-body lipolysis, and possibly a range of additional metabolic defects in several other organs [1]. Modern

\footnotetext{
*Correspondence: maricassol@unochapeco.edu.br

2 School of Medicine of Unochapecó University, Bairro Efapi, Chapecó, SC 89809-900, Brazil

Full list of author information is available at the end of the article
}

genetic analysis is unquestionably one of the most powerful research tools in complex diseases such as diabetes. It has been estimated that $30-70 \%$ of the risk of development of T2DM may be associated with genetic factors [2].

About $40 \%$ of the diabetic subjects with fasting glucose levels above $120 \mathrm{mg} / \mathrm{dL}$ and $90 \%$ of those with glycosylated hemoglobin A1C (HbA1c) above 7\% have abnormal postprandial glucose excursions [3]. Postprandial hyperglycemia has an estimated $30 \%$ contribution to the overall HbA1c concentration, and HbA1c levels, in turn, are proportional to the time in which the body remains 
in a postprandial state [3]. Even though T2DM is a polygenic disease with a wide range of phenotypic expression, the knowledge of the genetic mechanisms involved in the development and manifestations of the disease is one of the best weapons to implement therapeutic and preventive measures.

Tracking of genetic polymorphisms (i.e., single nucleotide differences between individuals) has identified single nucleotide polymorphisms (SNP) in the transcription factor 7-like 2 (TCF7L2) gene located in chromosome 10q25.2-10q25.3 with strong association with T2DM and impaired insulin secretion. This is a fundamental breakthrough in the understanding of the genetics in T2DM $[4,5]$. An important meta-analysis has associated one such SNP, the TCF7L2 rs7903146 variant, with an allelic odds ratio of 1.46 of T2DM development, making this the strongest known genetic risk factor for the disease [6]. TCF7L2 is mostly expressed in adipose tissues (visceral and subcutaneous), followed by liver, pancreatic islets, brain and other tissues [7, 8]. In contrast, TCF7L2 expression in the skeletal muscle is very low compared with other tissues [9]. The impact on diabetes of the rs7903146 variant of the TCF7L2 or other variants of the gene associated with T2DM appears to be mediated by decreased insulin secretion associated or not with defects in insulin processing $[4,5,10-12]$, reduced effects of glucagon-like peptide-1 (GLP-1) [13, 14], increased hepatic glucose production $[10,11,13]$, and insulin resistance $[8,15]$. This occurs because TCF7L2 is expressed in a broad spatial domain, including tissues with important roles in glucose metabolism. This raises the possibility that TCF7L2 may not regulate the glucose metabolism in vivo primarily through actions on beta cells, but rather through actions on extrapancreatic tissues which remain poorly characterized [15].

In this study, we performed a detailed metabolic characterization of adults with T2DM with and without the TCF7L2 rs7903146 risk $\mathrm{T}$ allele. In addition, we investigated the profiles of plasma insulin, proinsulin, C-peptide, glucagon, GLP-1 and plasma glucose during a 4-h meal test to explore some influences of the TCF7L2 genotype on glucose metabolism.

\section{Methods}

Blood for DNA extraction and biochemical and hormonal assessments was collected from 162 individuals diagnosed with T2DM. The study was approved by the Ethics Committee of the HC-FMUSP (CAPPesq0261/09) at Universidade de São Paulo and was performed according to the Declaration of Helsinki. All subjects gave written informed consent to participate and for publication data.

We selected 182 individuals with T2DM with disease duration $<10$ years, body mass index (BMI) between 25 and $35 \mathrm{~kg} / \mathrm{m}^{2}$, aged $45-65$ years, and nonusers of insulin, DPP-4 inhibitors, or GLP-1 mimetics. The participants were recruited from the endocrinology outpatient clinic at HC-FMUSP and from campaigns celebrating the World Diabetes Day. After the exclusion of patients with nephropathy, liver disease, and severe heart disease, 162 patients remained in the study and a subset of 56 individuals was paired according to genotype $C C$ versus $C T /$ TT and phenotypic variables (diabetes duration, BMI, and age) were selected for a mixed-meal test.

The individuals have had DM2 for $5.6 \pm 3.5$ years and without previous treatment with insulin, dipeptidyl peptidase 4 (DPP-4) inhibitors, or GLP-1 agonists. Subjects had a mean age of $57.4 \pm 7.1$ years, body mass index (BMI) of $30.5 \pm 5.2 \mathrm{~kg} / \mathrm{m}^{2}$, and mean $\mathrm{HbAlc}$ of $7.6 \pm 1.79 \%$. The participants were in good health, as determined by their medical histories, physical examinations, and screening blood tests. All subjects were genotyped for the TCF7L2 polymorphic variant rs7903146. Levels of blood glucose, HbA1c, HDL, uric acid, insulin, and C-peptide were compared in carriers and noncarriers of the risk $\mathrm{T}$ allele (CT/TT and $\mathrm{CC}$ genotypes, respectively). Treatment of diabetes included metformin alone or in association with a sulfonylurea.

A subset of 56 patients, 34 women, was paired according to phenotypic variables (diabetes duration, BMI $25-35 \mathrm{~kg} / \mathrm{m}^{2}$, and ages $45-55$ or $56-65$ years old) were selected for a mixed-meal test, which consisted of a 500 -calorie breakfast comprised of $50 \%$ carbohydrates, $30 \%$ protein, and $20 \%$ fat. Sulfonylureas were discontinued for $24 \mathrm{~h}$ before the test. Blood samples were collected at time points 0 (or baseline, corresponding to the start of the meal) and after 15, 30, 45, 60, 90, 120, 180, and $240 \mathrm{~min}$ for measurement of glucose, insulin, proinsulin, C-peptide, glucagon and GLP-1. Baseline measurements also included levels of TNF- $\alpha$, interleukin-6 (IL-6), C-reactive protein (CRP), and HbA1c.

For measurement of blood glucose levels, we used an enzymatic colorimetric method (system glucose oxidase-peroxidase, GOD-ANA Lab test, Brazil). Plasmatic concentrations of insulin, proinsulin, C-peptide, and glucagon were determined by double-antibody, liquid phase radioimmunoassay (Millipore Corporation, Billerica, USA). Plasma concentrations of active GLP-1 were measured with an ELISA kit (Millipore Corporation, Billerica, USA). We used the homeostasis model assessment (HOMA) calculator (available at https://www.dtu.ox.ac. $\mathrm{uk} /$ homacalculator/) to estimate the degree of beta cell function (\%B), and insulin sensitivity $(\% \mathrm{~S})$ and resistance (IR, which is the reciprocal of S\% $[100 / \% \mathrm{~S}]$ ) in the overall cohort using baseline glucose and C-peptide levels. Beta cell function was also evaluated with the insulinogenic index (or insulin secretion index, $\mathrm{IGI}_{30}$ ) using the early 
postprandial insulin response. The index is calculated by the increase in plasma insulin level $30 \mathrm{~min}$ after the meal [(insulin at $30 \mathrm{~min}$ - fasting insulin)/(glucose at 30 $\min$ - fasting glucose)].

\section{Genotyping of TCF7L2 rs7903146}

Blood samples were obtained from each subject, and genomic DNA was extracted from peripheral blood leukocytes using the salting-out method. The rs7903146 SNP was genotyped using TaqMan SNP Genotyping Assays (Applied Biosystems, Foster City, CA, USA) according to the manufacturer's instructions. The genotyping success rate was $96.4 \%$. Direct sequencing of 10 samples with different genotypes was performed for quality control of the assays and the concordance between assays was $100 \%$.

\section{Statistical analysis}

Qualitative characteristics of the patients were described according to each genotype, and their association with the genotypes was assessed with the Chi square test. Laboratory assessments and anthropometric characteristics were described according to each genotype and compared among the genotypes with analysis of variance (ANOVA) or the Kruskal-Wallis test. For the rs7903146 SNP, we evaluated the genotypes CC, CT, and TT separately, and then the $\mathrm{CT}$ and $\mathrm{TT}$ in combination. The categories were then compared using Student's $t$ test or the Mann-Whitney $U$ test, further, in Tables 1 and 2 footnote.

The analyses of the meal test were conducted by groups ( $\mathrm{CC}$ and $\mathrm{TT} / \mathrm{CT})$, time points, and evaluation of the curve (test times) using summary measures. Comparisons between groups, time points, and test times were assessed with ANOVA. For measures showing statistically significant differences, we performed multiple Bonferroni comparisons or contrasts to estimate the differences and verify in which groups or moments they occurred. In the follow-up curve, we compared the groups at each moment using Scheffés multiple comparisons test.

\section{Results}

The clinical characteristics of the overall cohort are presented in Table 1. We observed that carriers of the $\mathrm{T}$ allele were younger at diabetes onset, which may suggest an increased susceptibility to the disease. These patients also differed from those in the CC group by presenting lower uric acid and higher HDL-cholesterol plasma levels, considered markers of peripheral insulin resistance. We also observed that carriers of the $\mathrm{T}$ allele had a lower neck-to-thigh ratio.

Mean C-peptide levels differed among the three genotypes of the rs7903146 variant $(p=0.040$ for $C C$ versus
Table 1 Laboratory characteristics of the overall cohort $(n=162)$ and results of the comparative tests

\begin{tabular}{|c|c|c|c|c|c|}
\hline Variable & rs7903146 & Mean & SD & $\mathbf{N}$ & $p$ \\
\hline \multirow[t]{2}{*}{ Age (years) } & $\mathrm{CC}$ & 58.42 & 6.15 & 67 & 0.054 \\
\hline & $\mathrm{CT} / \mathrm{TT}$ & 56.26 & 7.96 & 95 & \\
\hline \multirow[t]{2}{*}{ Age/diagnosis (years) } & CC & 53.27 & 6.66 & 67 & $0.047^{*}$ \\
\hline & $\mathrm{CT} / \mathrm{TT}$ & 50.88 & 8.47 & 94 & \\
\hline \multirow[t]{2}{*}{$\mathrm{BMI}\left(\mathrm{kg} / \mathrm{m}^{2}\right)$} & $\mathrm{CC}$ & 30.43 & 4.51 & 67 & 0.823 \\
\hline & $\mathrm{CT} / \mathrm{TT}$ & 30.61 & 5.44 & 95 & \\
\hline \multirow[t]{2}{*}{ Waist (cm) } & $\mathrm{CC}$ & 103.43 & 11.18 & 67 & 0.804 \\
\hline & $\mathrm{CT} / \mathrm{TT}$ & 102.99 & 10.92 & 94 & \\
\hline \multirow[t]{2}{*}{$\operatorname{Neck}(\mathrm{cm})$} & $\mathrm{CC}$ & 38.69 & 3.43 & 67 & 0.053 \\
\hline & $\mathrm{CT/TT}$ & 37.63 & 3.34 & 93 & \\
\hline \multirow[t]{2}{*}{$\mathrm{N} / \mathrm{T}$ ratio } & $\mathrm{CC}$ & 0.67 & 0.08 & 67 & $0.008^{*}$ \\
\hline & $\mathrm{CТ/TТ}$ & 0.64 & 0.07 & 93 & \\
\hline \multirow[t]{2}{*}{ Blood glucose (ng/dL) } & CC & 146.69 & 59.48 & 61 & 0.988 \\
\hline & $\mathrm{CT} / \mathrm{TT}$ & 146.84 & 58.63 & 91 & \\
\hline \multirow[t]{2}{*}{ HbA1c (\%) } & $\mathrm{CC}$ & 7.57 & 1.70 & 61 & 0.943 \\
\hline & $\mathrm{CT} / \mathrm{TT}$ & 7.59 & 1.78 & 87 & \\
\hline \multirow[t]{2}{*}{$\mathrm{HDL}(\mathrm{mg} / \mathrm{dL})$} & $\mathrm{CC}$ & 46.48 & 10.88 & 60 & $0.041^{*}$ \\
\hline & $\mathrm{CT} / \mathrm{TT}$ & 50.89 & 13.87 & 87 & \\
\hline \multirow[t]{2}{*}{ Uric acid (mg/dL) } & $\mathrm{CC}$ & 5.93 & 1.78 & 53 & $0.017^{*}$ \\
\hline & $\mathrm{CT} / \mathrm{TT}$ & 5.23 & 1.40 & 83 & \\
\hline \multirow[t]{2}{*}{ Insulin ( $\mu \mathrm{IU} / \mathrm{mL})$} & CC & 17.65 & 12.13 & 63 & 0.099 \\
\hline & $\mathrm{CT} / \mathrm{TT}$ & 14.55 & 10.80 & 90 & \\
\hline \multirow[t]{2}{*}{ C-peptide (ng/mL) } & $\mathrm{CC}$ & 3.47 & 1.65 & 63 & $0.015^{*}$ \\
\hline & $\mathrm{CT} / \mathrm{TT}$ & 2.87 & 1.36 & 93 & \\
\hline
\end{tabular}

All analyses were performed with Student's $t$ test, with the exception of the comparison of C-peptide levels, which was assessed with the Mann-Whitney test

$S D$ standard deviation; $B M I$ body mass index; $N / T$ ratio neck-to-thigh ratio; $H b A 1 C$ glycosylated hemoglobin

${ }^{*} \mathrm{p}<0.05$

CT versus TT). Carriers of the rs7903146 T allele $(n=95)$ showed lower baseline plasma concentrations of C-peptide when compared with non-carriers of the allele. The difference was statistically greater in CC wild-type homozygous individuals compared with CT $(p=0.029)$ and TT $(\mathrm{p}=0.037)$ carriers.

Of the 56 individuals who participated in the mixedmeal test, 26 were carriers of the $\mathrm{CC}$ variant, and 30 were carriers of the CT/TT variants of the rs7903146. Both groups had similar weight, BMI, and plasma concentrations of glucose and HbA1c (Table 2). Plasma concentrations of glucose, glucagon and GLP-1 exhibited similar behavior during the mixed-meal test in both the CC and $\mathrm{CT} / \mathrm{TT}$ groups. In contrast, plasma concentrations of insulin during the test were significantly higher in CT/TT subjects at time points from 30 to $120 \mathrm{~min}$ when compared with CC individuals $(\mathrm{p}<0.05)(\mathrm{Fig} .1)$. Insulin levels 
Table 2 Clinical characteristics of the subgroup of 56 patients who participated in the mixed-meal test

\begin{tabular}{|c|c|c|c|c|c|c|c|c|}
\hline Variable & rs7903146 & Mean & SD & Median & Minimum & Maximum & $\mathbf{N}$ & $\mathrm{p}$ \\
\hline \multirow[t]{2}{*}{ Age (years) } & CC & 59.65 & 6.07 & 60.50 & 47 & 69 & 26 & 0.310 \\
\hline & $\mathrm{CT} / \mathrm{TT}$ & 57.80 & 7.28 & 58.50 & 40 & 71 & 30 & \\
\hline \multirow[t]{2}{*}{$\mathrm{BMI}\left(\mathrm{kg} / \mathrm{m}^{2}\right)$} & $\mathrm{CC}$ & 30.29 & 3.45 & 30.02 & 23.7 & 36.9 & 26 & 0.704 \\
\hline & $\mathrm{CT} / \mathrm{TT}$ & 29.86 & 4.74 & 29.34 & 21.1 & 39.4 & 30 & \\
\hline \multirow[t]{2}{*}{ Disease duration (years) } & $\mathrm{CC}$ & 6.31 & 3.90 & 5.00 & 1 & 13 & 26 & 0.197 \\
\hline & $\mathrm{CT} / \mathrm{TT}$ & 4.93 & 3.34 & 4.50 & 0 & 12 & 30 & \\
\hline \multirow[t]{2}{*}{ HbA1c (\%) } & CC & 7.79 & 1.86 & 7.50 & 5.4 & 11.8 & 21 & 0.054 \\
\hline & $\mathrm{CT} / \mathrm{TT}$ & 6.89 & 0.95 & 6.85 & 5.5 & 9 & 28 & \\
\hline \multirow[t]{2}{*}{ Insulin (mIU/mL) } & $\mathrm{CC}$ & 15.36 & 8.00 & 13.40 & 4.8 & 30.3 & 24 & 0.483 \\
\hline & СТ/TT & 13.79 & 8.09 & 11.80 & 4 & 42 & 29 & \\
\hline \multirow[t]{2}{*}{ C-peptide (ng/mL) } & CC & 3.37 & 1.79 & 2.90 & 0.8 & 7.6 & 25 & 0.154 \\
\hline & СТ/ТT & 2.80 & 0.90 & 2.70 & 1.3 & 5 & 30 & \\
\hline
\end{tabular}

All analyses were performed with Student's $t$ test, with the exception of the comparison of disease duration, which was assessed with the Mann-Whitney test $S D$ standard deviation; BMI body mass index; HbA1c glycosylated hemoglobin

peaked at $90 \mathrm{~min}$ in the CT/TT group and at $120 \mathrm{~min}$ in the CC group. Similarly, plasma concentrations of proinsulin were also higher in $\mathrm{CT} / \mathrm{TT}$ subjects, but in this case it was at almost all time points, from 45 to $240 \mathrm{~min}$, compared with $C C$ individuals $(\mathrm{p}<0.05)$. Additionally, there was no significant difference in $\mathrm{IGI}_{30}$ in $\mathrm{CC}$ individuals compared with $\mathrm{CT} / \mathrm{TT}$ individuals $(1.52 \pm 3.49$ versus $1.31 \pm 1.95$, respectively, $p=$ non-significant).

Using baseline glucose and C-peptide concentrations to calculate the HOMA index, carriers compared with noncarriers of the $\mathrm{T}$ allele had higher $\% \mathrm{~S}(\mathrm{p}=0.021)$, lower IR $(\mathrm{p}=0.020)$, and similar $\% \mathrm{~B}(\mathrm{p}=0.095)$. There was no difference in baseline levels of CRP and IL- 6 in both genotype groups, but TNF- $\alpha$ values were higher in the CT/TT group when compared with the CC group ( $<<0.001)$.

\section{Discussion}

The results of our study demonstrate that the presence of the rs7903146 $\mathrm{T}$ allele in the TCF7L2 gene in individuals with T2DM was associated with increased postprandial secretion of insulin, proinsulin, and C-peptide when compared with the absence of the allele. In contrast, the serum concentrations of glucagon and glucose in response to the meal test were similar in all individuals regardless of genotype. These results show that beta cells respond differently to a glucose overload in a mixed meal when carriers of the rs7903146 CT and TT variants are compared with carriers of the CC genotype. However, the results of the analyses performed after the meal also suggest that carriers of the CT/TT variants may also show greater insulin resistance. This contrasts with the results of the HOMA analysis, which used baseline values, reflecting the limitations of using HOMA and the importance of performing a postprandial analysis. And also reinforce the likely role of TCF7L2 in incretin effect that occurs in the postprandial state. These results should be interpreted considering an absence of differences in weight or glucotoxicity in the individuals included in our study since both groups had similar BMI and plasma concentrations of glucose, glucagon, and HbA1c. Of note, GLP-1 is secreted with a magnitude proportional to the caloric content of the meal. Although carbohydrates seem to be the strongest triggers of GLP-1 secretion, ingested fat also reliably stimulates GLP-1 release [16]. In contrast, dietary proteins have a variable effect on incretin release [17].

Most of previous studies assessing the impact of TCF7L2 SNP variants in the pathogenesis of T2DM have focused on the role of the gene in beta cells. However, some studies have demonstrated a negative effect of the TCF7L2 rs7903146 T allele on insulin sensitivity, showing that carriers of the $\mathrm{T}$ allele may present reduced insulin sensitivity $[18,19]$. Moreover, it has been recently demonstrated that mice overexpressing TCF7L2 display reciprocal phenotypes, including increased plasma insulin levels, and glucose intolerance due to peripheral insulin resistance, indicating that overexpression of TCF7L2 leads to a phenotype of T2DM [8]. In our study, we found no differences in $\mathrm{IGI}_{30}$ after the mixed-meal test. However, there was a difference in plasma concentrations of insulin and C-peptide at time points $30-120 \mathrm{~min}$ in the curve, which corresponds to moments with higher insulin levels in $\mathrm{T}$ allele carriers. Additionally, a study using a genetic approach in mice showed that removal of the TCF7L2 gene from beta cells did not affect their function, whereas manipulating TCF7L2 levels in the liver had major effects on metabolism [20]. These authors also showed that adult mice with knockout of the liver-specific TCF7L2 gene 

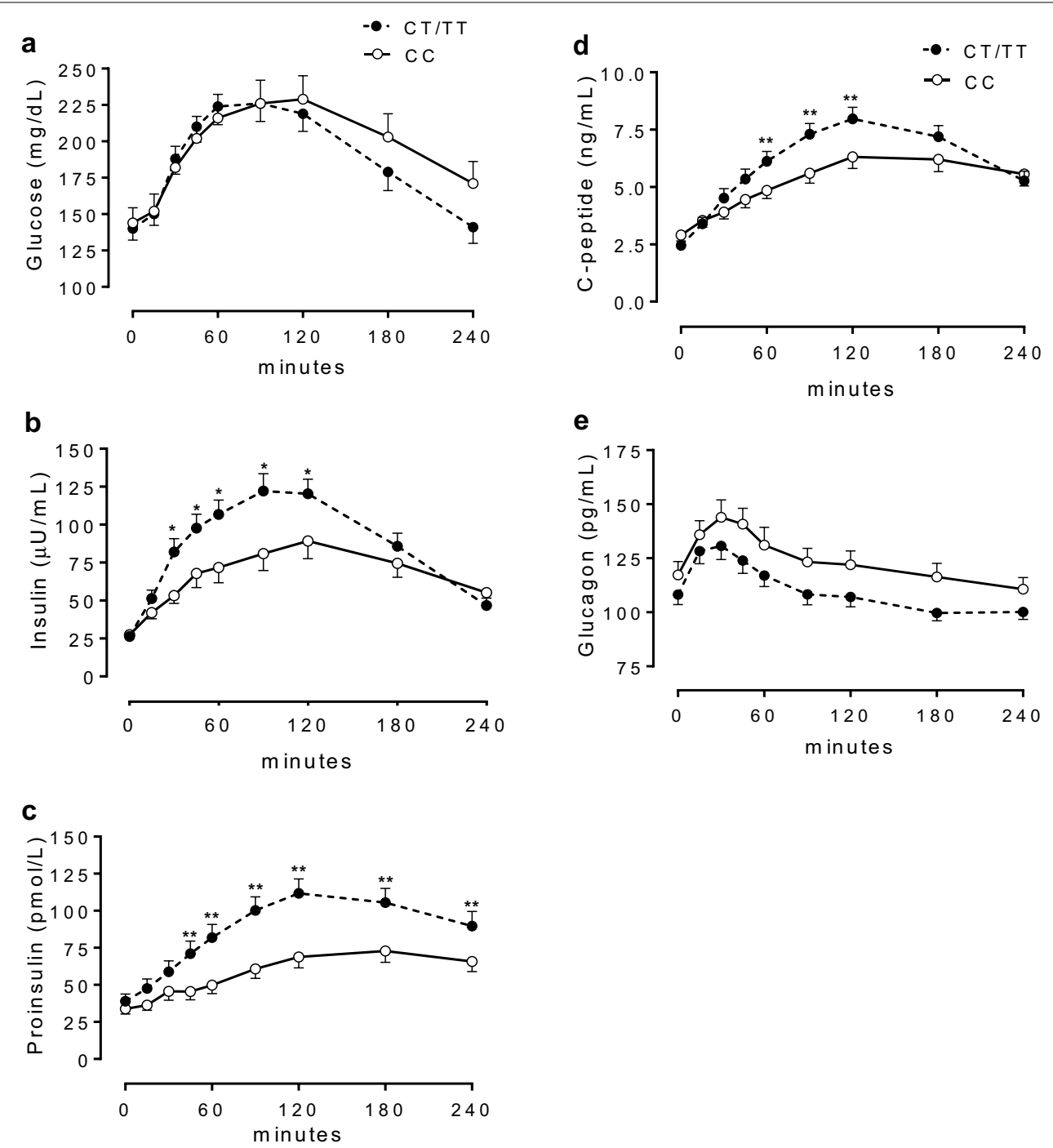

Fig. 1 Plasma concentrations of glucose (a), insulin (b), proinsulin (c), C-peptide (d) and glucagon (e) in 26 and 30 carriers of the CC and CT/ TT genotypes, respectively, during the mixed-meal test. CT/TT subjects, compared with CC individuals, had higher plasma levels of insulin and C-peptide at 30-120 $\min (p<0.05)$ and proinsulin at 45-240 $\min (p<0.05)$

have reduced production of hepatic glucose during fasting and improved glucose homeostasis when maintained on a high-fat diet [20].

The results of our study show that carriers of the rs7903146 T allele of the TCF7L2 gene present lower baseline plasma concentrations of C-peptide than noncarriers, with similar plasma concentrations of glucose and glucagon. These data are in line with those of other studies that suggest that the diabetogenic effect associated with TCF7L2 may be expressed on insulin secretion $[4,5,18]$. However, we could not find lower insulin secretion in T allele carriers when we evaluated the $\mathrm{IGI}_{30}$. Grant et al. [21] suggested that variants in TCF7L2 affect an individual's susceptibility to T2DM through impaired transcriptional regulation of the insulinotropic hormone GLP1-1, encoded by GCG and expressed in the brain and gut. An alternative hypothesis to explain our findings is that variants in TCF7L2 disrupt adipogenesis and/or adipocyte function by altering the transcriptional regulation of PPARG leading to deposition of triglycerides in peripheral tissues (i.e., liver and muscle) and resulting in insulin resistance or that the defect on insulin secretion would be exacerbated by acute free fatty acid (FFA)-induced insulin resistance $[19,21,22]$. Although this study did not aim at evaluating peripheral insulin sensitivity in carriers of the $\mathrm{T}$ allele, the results suggest that further investigation should be made in this regard. 
We would like to point out the relatively small number of participants $(n=56)$ who underwent to the mix-meal test as a limitations of our study, there is a potential contribution of this for not finding statistical differences on some of the variables. And another limitation of the study is that other TCF7L2 SNPs with more weak association with T2DM were not studied, e.g., rs7901695, rs7896340, rs11196205, and rs12255372, they could have functional impacts.

\section{Conclusions}

We conclude that T2DM individuals carrying the rs7903146 T allele of the TCF7L2 gene have different patterns of response at baseline and to a 500-calorie meal test, suggesting at baseline a worse quality function of the beta cells. After meal test we verified increased postprandial secretion of insulin, proinsulin, and C-peptide in the rs7903146 $\mathrm{T}$ allele carriers when compared with the absence of the allele. These data support that TCF7L2 plays key roles in glucose metabolism through actions beyond those of the pancreatic beta cells and point out to functionally opposing cell-type specific effects for TCF7L2 on maintaining a balanced glucose metabolism. These findings reinforce the role of TCF7L2 in non-pancreatic tissues, and are consistent with our hypotheses of the occurrence of correlation between TCF7L2 in both insulin secretion and postprandial insulin sensitivity. Uncovering of these roles may lead to new therapeutic targets for T2DM.

\section{Authors' contributions \\ MCF and RFS designed the study, participated directly in the execution of the study, participated in the analysis of the plasma metabolites, performed the statistical analysis, and wrote and edited the manuscript. These authors are the guarantors of the study and, as such, had full access to all data in the study and take responsibility for the integrity of the data and the accuracy of the data analysis. MCF was also responsible for the treatment, recruitment, and follow-up of the patients, and for obtaining the written consent from all the participants. MERS is the head of the laboratory that analyzed the samples and participated directly in the execution of the study and revision of the manuscript. RTF and MCA-M were responsible for the recruitment of the individuals, evaluation of anthropometrical and clinical characteristics, and laboratory analysis. RTF also contributed in the statistical analysis. SA participated in the revision of the manuscript. All authors read and approved the final manuscript.}

\section{Author details}

${ }^{1}$ Laboratory of Medical Investigation LIM-18, Division of Endocrinology, School of Medicine, University of Sao Paulo, Av Dr Arnaldo, 455 room 3324, Sao Paulo, SP 01246903, Brazil. ${ }^{2}$ School of Medicine of Unochapecó University, Bairro Efapi, Chapecó, SC 89809-900, Brazil.

\section{Acknowledgements}

The authors would like to thank State of São Paulo Research Foundation [Fundação de Amparo à Pesquisa do Estado de São Paulo, FAPESP, Brazil—N 2010/17943-7], the National Institutes of Health [NHLBI, Grant, 2R01HL33881], and the Office of Research and Development [Medical Service, Department of Veterans Affairs SA and WE Executive Committee] for the support granted through the Women in Endocrinology Young Investigator Award to Mari Cassol Ferreira, M.D., Ph.D. for the presentation of the abstract of this study at the Annual Meeting of the Endocrine Society in 2013.

\section{Competing interests}

The authors declare that they have no competing interests.

\section{Availability of data and materials}

The datasets during and/or analysed during the current study available from the corresponding author on reasonable request.

\section{Consent for publication}

Not Applicable.

\section{Ethics approval and consent to participate}

The study was approved by the Ethics Committee of the HC-FMUSP (CAPPesq0261/09) at Universidade de São Paulo and was performed according to the Declaration of Helsinki.

All subjects gave written informed consent to participate.

\section{Funding}

The study was funded by the São Paulo Research Foundation (FAPESP—2010/17943-7), São Paulo, Brazil.

\section{Publisher's Note}

Springer Nature remains neutral with regard to jurisdictional claims in published maps and institutional affiliations.

Received: 28 February 2018 Accepted: 17 April 2018

Published online: 26 April 2018

\section{References}

1. Vaag A. On the pathophysiology of late onset non-insulin dependent diabetes mellitus. Current controversies and new insights. Dan Med Bull. 1999;46(3):197-234.

2. Poulsen P, Kyvik KO, Vaag A, Beck-Nielsen H. Heritability of type II (noninsulin-dependent) diabetes mellitus and abnormal glucose tolerancea population-based twin study. Diabetologia. 1999;42(2):139-45.

3. Bonora E, Calcaterra F, Lombardi S, Bonfante N, Formentini G, Bonadonna RC, Muggeo M. Plasma glucose levels throughout the day and $\mathrm{HbA}(1 \mathrm{C})$ interrelationships in type 2 diabetes: implications for treatment and monitoring of metabolic control. Diabetes Care. 2001;24(12):2023-9.

4. Dahlgren A, Zethelius B, Jensevik K, Syvanen AC, Berne C. Variants of the TCF7L2 gene are associated with beta cell dysfunction and confer an increased risk of type 2 diabetes mellitus in the ULSAM cohort of Swedish elderly men. Diabetologia. 2007;50(9):1852-7.

5. Lyssenko V, Lupi R, Marchetti P, Del Guerra S, Orho-Melander M, Almgren P, Sjogren M, Ling C, Eriksson KF, Lethagen AL, Mancarella R, Berglund G, Tuomi T, Nilsson P, Del Prato S, Groop L. Mechanisms by which common variants in the TCF7L2 gene increase risk of type 2 diabetes. J Clin Invest. 2007;117(8):2155-63.

6. Cauchi S, El Achhab Y, Choquet H, Dina C, Krempler F, Weitgasser R, Nejjari C, Patsch W, Chikri M, Meyre D, Froguel P. TCF7L2 is reproducibly associated with type 2 diabetes in various ethnic groups: a global metaanalysis. J Mol Med. 2007;85(7):777-82.

7. Norton L, Fourcaudot M, Abdul-Ghani MA, Winnier D, Mehta FF, Jenkinson CP, Defronzo RA. Chromatin occupancy of transcription factor 7-like 2 (TCF7L2) and its role in hepatic glucose metabolism. Diabetologia. 2007:54(12):3132-42.

8. Savic D, Ye H, Aneas I, Park SY, Bell GI, Nobrega MA. Alterations in TCF7L2 expression define its role as a key regulator of glucose metabolism. Genome Res. 2011;21(9):1417-25.

9. Osmark P, Hansson O, Jonsson A, Ronn T, Groop L, Renstrom E. Unique splicing pattern of the TCF7L2 gene in human pancreatic islets. Diabetologia. 2009;52(5):850-4.

10. Loos RJ, Franks PW, Francis RW, Barroso I, Gribble FM, Savage DB, Ong KK, O'Rahilly S, Wareham NJ. TCF7L2 polymorphisms modulate proinsulin levels and beta-cell function in a British Europid population. Diabetes. 2007;56(7):1943-7. 
11. Stolerman ES, Manning AK, MCAteer JB, Fox CS, Dupuis J, Meigs JB, Florez JC. TCF7L2 variants are associated with increased proinsulin/insulin ratios but not obesity traits in the Framingham Heart Study. Diabetologia. 2009;52(4):614-20.

12. da Silva Xavier G, Mondragon A, Sun G, Chen L, McGinty JA, French PM, Rutter GA. Abnormal glucose tolerance and insulin secretion in pancreasspecific Tcf7l2-null mice. Diabetologia. 2012;55(10):2667-76.

13. Pilgaard K, Jensen CB, Schou JH, Lyssenko V, Wegner L, Brons C, Vilsboll T, Hansen T, Madsbad S, Holst JJ, Volund A, Poulsen P, Groop L, Pedersen O, Vaag AA. The T allele of rs 7903146 TCF7L2 is associated with impaired insulinotropic action of incretin hormones, reduced $24 \mathrm{~h}$ profiles of plasma insulin and glucagon, and increased hepatic glucose production in young healthy men. Diabetologia. 2009;52(7):1298-307.

14. Schafer SA, Tschritter O, Machicao F, van Haeften TW, Haring HU, Fritsche A. Impaired glucagon-like peptide-1-induced insulin secretion in carriers of transcription factor 7-like 2 (TCF7L2) gene polymorphisms. Diabetologia. 2007;50(12):2443-50.

15. Nobrega MA. TCF7L2 and glucose metabolism: time to look beyond the pancreas. Diabetes. 2015;62(3):706-8.

16. Falko JM, Crockett SE, Cataland S, Mazzaferri EL. Gastric inhibitory polypeptide (GIP) stimulated by fat ingestion in man. J Clin Endocrinol Metab. 1975;41(2):260-5.
17. Carr RD, Larsen MO, Winzell MS, Jelic K, Lindgren O, Deacon CF, Ahren B. Incretin and islet hormonal responses to fat and protein ingestion in healthy men. Am J Physiol Endocrinol Metab. 2008;295(4):E779-84.

18. Wegner L, Hussain MS, Pilgaard K, Hansen T, Pedersen O, Vaag A, Poulsen P. Impact of TCF7L2 rs7903146 on insulin secretion and action in young and elderly Danish twins. J Clin Endocrinol Metab. 2008;93(10):4013-9.

19. Damcott CM, Pollin TI, Reinhart LJ, Ott SH, Shen H, Silver KD, Mitchell BD, Shuldiner AR. Polymorphisms in the transcription factor 7-like 2 (TCF7L2) gene are associated with type 2 diabetes in the Amish: replication and evidence for a role in both insulin secretion and insulin resistance. Diabetes. 2006:55(9):2654-9.

20. Boj SF, van Es JH, Huch M, Li VS, Jose A, Fillat C, Clevers H. Diabetes risk gene and Wnt effector Tcf712/TCF4 controls hepatic response to perinatal and adult metabolic demand. Cell. 2012;151(7):1595-607.

21. Grant SF, Thorleifsson G, Reynisdottir I, Benediktsson R, Manolescu A, Sainz J, Kong A, Stefansson K. Variant of transcription factor 7-like 2 (TCF7L2) gene confers risk of type 2 diabetes. Nat Genet. 2006:38(3):320-3

22. Shah M, Varghese RT, Miles JM, et al. TCF7L2 Genotype and alpha-cell function in humans without diabetes. Diabetes. 2016:65:371-80.
Ready to submit your research? Choose BMC and benefit from:

- fast, convenient online submission

- thorough peer review by experienced researchers in your field

- rapid publication on acceptance

- support for research data, including large and complex data types

- gold Open Access which fosters wider collaboration and increased citations

- maximum visibility for your research: over 100M website views per year

At BMC, research is always in progress.

Learn more biomedcentral.com/submissions 